\title{
Analysis of renewable energy sources and a heat storage tank application in a district heating substation
}

\author{
Kamil Chłosta ${ }^{1,2 *}$, Wiesław Zima ${ }^{1}$ \\ ${ }^{1}$ Cracow University of Technology, Al. Jana Pawła II 37, 31-864 Kraków, Poland \\ ${ }^{2}$ PGE Energia Ciepła S.A., ul. Złota 59, 00-120 Warszawa, Poland
}

\begin{abstract}
The study verifies the potential application of renewable energy sources in a district heating substation. Different operating configurations of heat sources have been analysed, including solar collectors, PV panels and air source heat pump. Concepts of regulating the water parameters in a substation have been analysed. Moreover, the potential impact of a heat storage tank application has been calculated using a genetic algorithm to find optimal operating conditions in a district heating substation. The analysis is based on measured yearly data.
\end{abstract}

\section{Introduction}

District heating systems are recognized worldwide as an efficient method for providing house heating. Nonetheless, the more stricter requirements of environmental regulations get, the less attractive the district heating could become for the consumers due to price increase fall-out. Thus, the thermal energy sector cannot remain stagnant and have to adjust to new regulations. With regard to Directive RED II, the district heating is subject to series of challenges, due to the need for $\mathrm{CO} 2$ emission reduction and direct connection to the construction sector [1]. In Poland, the construction sector now has to fulfil conditions stated by Energy Performance of Buildings Directive, which is reflected in the Construction Law [2]. Not only do the new buildings require improved energy efficiency, but also have to declare sufficient mix of mandatory renewable thermal power sources [3]. The imposed regulations induce the development of efficient energy systems, promote renewable energy sources and encourage to recover more and more energy from waste heat and cold [4].

Sources indicate that the crucial factor in enabling the increase of shares of renewables is to lower the district heating operating temperature. Apart from more traditional ways of heat loss reduction in district heating networks, the application of decentralized heat sources instead of traditional centralized heat production can decrease the network operating temperature, improve overall system efficiency by reduction of distribution losses and gradually paves the way for more and more renewable energy sources to increase its shares in the district heating energy supply portfolios [5].

\subsection{Heat pumps application in district heating}

Depending on the electricity prices heat pumps could be a viable option to avoid $\mathrm{CO}_{2}$ emissions and increase the shares of renewables in district heating supply sources [5], especially when the electricity to power heat pump compressor would not origin from non-renewable energy resources. A potential solution would be to install PV panels to periodically supply the power to heat pump compressor, simultaneously decreasing the shares of non-renewable sources in thermal energy supply and allowing more new buildings to be connected to the DH network by meeting the policy requirements [1-3]. Implementation of air-source heat pump in DH substations would allow the COP to achieve higher values, and reduce operational and investment costs in comparison to heat pump installation on higher parameters of district heating network [6]. If given proper policy support to allow the heat pump to be operated on a varying marketdependent electricity prices in conjunction with optimal management of such assets with smart heat storage solutions, the HP operating costs could decrease significantly. However, in a decentralised scenario, where existing district heating network in high density cities would be involved it could be challenging to implement such a system design, as it would involve multiple parties and infrastructure stakeholders to come to complicated agreements, ensure available space and develop proper additional infrastructure.

Another viable alternative would be to use of energy of the heating water on the return as a source heat for the heat pump [6]. In light of the mentioned regulations [1$3]$, it would only be a viable option if $\mathrm{DH}$ water on return would be considered as a renewable source or a waste

\footnotetext{
* Corresponding author: kamilchlosta@gmail.com
} 
heat. Further decrease of DH return temperature would allow to further increase the efficiency of such heat sources as CHP gas engine units which gain more and more popularity nowadays, as the thermal energy sector overgoes transition to cleaner gas-based assets (compared to coal-fired CHP plants). As CHP gasengines require low temperature water (or other medium) parameters for efficient cooling, the efficiency by utilising all wasted heat (and the necessity for investing in additional cooling systems and its maintenance) in the cooling process would increase [7]. Thus, the lower the return temperature gets, the more efficiently can the CHP gas engines operate. Moreover, DH return temperature seems to be relatively in constant value range throughout the year, assuring the potential for achieving higher COP values [6].

\subsection{Solar thermal collectors in District Heating}

Solar thermal energy is recognized as a feasible technology for hot water production and low temperature space heating in residential buildings. In context of district heating application the technology poses numerous challenges. Firstly, in order for solar thermal collectors is DH network to be economically viable, the supply temperature has to be reduced [5]. Hence, the building heating installation need to be adjusted accordingly. A base root challenge of solar thermal is that the heat demand is not aligned with solar thermal power supply. To increase the shares of solar thermal in the thermal power supply mix it is necessary to implement a heat storage system. There are two most popular approaches when it comes to heat storage when solar thermal technology is involved. The first solution is a long-term seasonal storages, that store solar heat gathered during the summer season until the heating season in winter. More common are daily-based heat storages, that store solar heat produced during the day to be used when the sunlight is absent, which result in more uniform heat demand profile distribution. Depending on the size of the storage the shares of thermal power utilised from solar thermal in district heating range from 10 to $50 \%$ [8]. Another important note is that solar thermal requires significantly more space in comparison to conventional CHP plants. Denmark has successfully incorporated many solar thermal fields into district heating networks, though, mostly in medium size cities and towns with access to more accessible land [9]. In addition, solar thermal collectors water temperature output is limited, though it seems as a viable solution to for domestic hot water preparation. Thus, the application in district heating substation should be a feasible solution when there is a separate heat exchanger installation foreseen for domestic hot water heating. This ensures enough temperature difference to successfully operate solar collector and cover significant part of demand for domestic hot water application.

\section{Methodology}

Analysed DH substation is located in a polish district heating system. The analysis is based on real historic measurement data, in hourly resolution concerning whole year of operation of the DH substation.

EBSILON Professional has been used to model and simulate operation of the district heating substation and subsequent scenarios including the renewable energy sources, notably air-source heat pump and PV panels. EBSILON Professional is the software for thermodynamic simulation of power and energy systems. The tool enables design and simulation of single system components as well as complex technological systems regarding power or heat production among other features [10].

Genetic Algorithm implementation [11-12] in R [13], using RStudio IDE [14], and several data manipulation and visualisation packages [15-19] is used to optimize the amount of energy produced during the periods of higher electricity prices. Firstly, a mathematical model has been developed in $\mathrm{R}$, that returns the objective function, being a sum of hourly income. The function parameters are modelled so that the stored energy has to reset at the end of each cycle. If the algorithm deviates, the appropriate punishing function is added to objective function to prevent the algorithm to return unrealistic arguments.

\section{Analysis}

It is the first attempt to develop viable solution that involves implementation of renewables in district heating substation equipped with heat storage tank. The analysis considers four different models each reflecting different scenarios and comparing the calculations to a simplified model based on measured yearly data to capture substation parameters dynamics. Moreover, the genetic algorithm [11] has been used to find optimal operating conditions of heat storage tank based on the assumption that the district heating has no thermal inertia (steady-state) and the access to polish day-ahead electricity market since the analysed district heating substation is located in a network powered by CHP plant. Thus, the maximization of the amount of energy produced during the time of the highest prices of electricity is possible, resulting in more profitable operation model for CHP plants. Heat storage capacity has been assumed to constant power instead of volume. Algorithm does not include volume, density and specific heat changes with temperature and its based solely on energy balance equation. Further developments are foreseen in the future.

The district heating substation subject to analysis has a contractual thermal capacity of $700 \mathrm{~kW}$, though the measurement data indicates $230 \mathrm{~kW}$ as a maximum demand value in measurement time domain. In the summer the median demand is equal to $30 \mathrm{~kW}$.

Figure 1 presents the district heating substation characteristics, including thermal power demand profile as well as supply and return temperature (from consumer side) distributions respectively. 


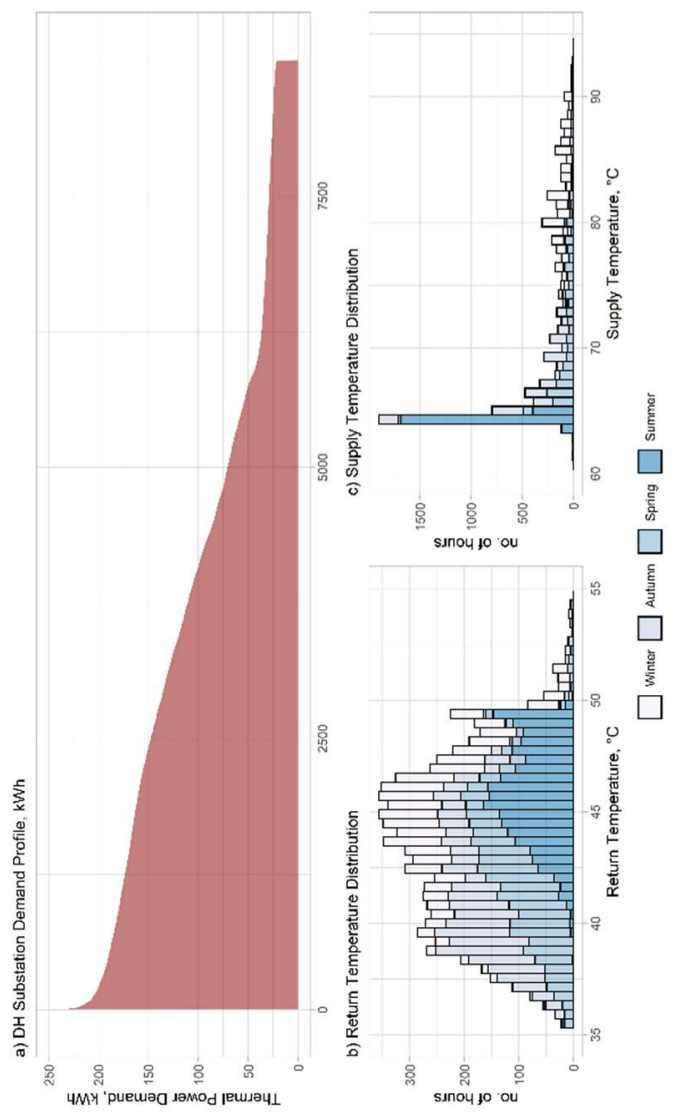

Fig. 1 DH substation characteristics: a) Thermal Power Demand Distribution, b) Return Temperature Distribution, c) Supply Temperature Distribution

Most of the time return temperature does not exceed $50^{\circ} \mathrm{C}$, and ranges from $35^{\circ} \mathrm{C}$ to $55^{\circ} \mathrm{C}$. Supply temperature ranges from $60^{\circ} \mathrm{C}$ to $95^{\circ} \mathrm{C}$ and the median is equal to $72^{\circ} \mathrm{C}$. The return temperature is too high to effectively apply solar thermal collectors.

\subsection{Existing district heating substation model}

A simplified model of existing district heating substation has been developed in EBSILON Professional software in order to compare the results to other models. Figure 2 presents the model scheme. On the left-hand side a heat exchanger is powered from the district heating. Heat is transported in substation water circuit to the consumers. Model allows to calculate parameters based on specified boundary conditions. In this case the model calculates the mass flow rates from the district heating as well as in substation circuit. The automation is set to control upper temperature difference between supply temperatures (DH supply and consumers supply temperatures). Another controller regulates the flow so that the consumers receive sufficient thermal power.

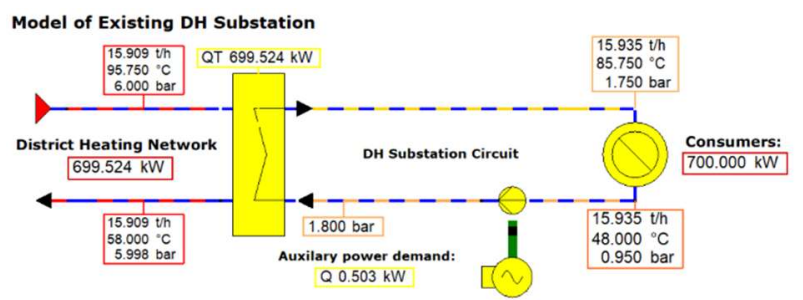

Fig. 2 Simplified model of existing district heating substation. Design state for contractual thermal capacity

\subsection{DH substation with heat storage}

The model of the district heating substation that utilizes heat storage is presented on figure 3 . However, the heat storage conditions are modelled outside EBSILON Professional, using a genetic algorithm to optimize objective function. The control scheme is analogous to previous base model, but incorporates another linear controller, that controls the mass flow rates in and out of the heat storage tank, so that the specified amount of thermal energy is stored in the tank.

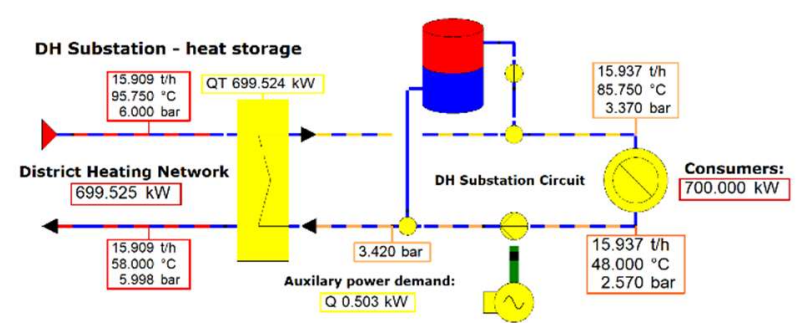

Fig. 3 Conceptual scheme of district heating substation operating with heat storage tank.

Figure 4 shows the underlying concept of optimization idea. When the electricity price is higher than average in given optimized time period, the heat storage tank is being charged proportionally to the deviation of the price from the average. When the electricity price is lower than average, then the heat storage tank is being discharged.

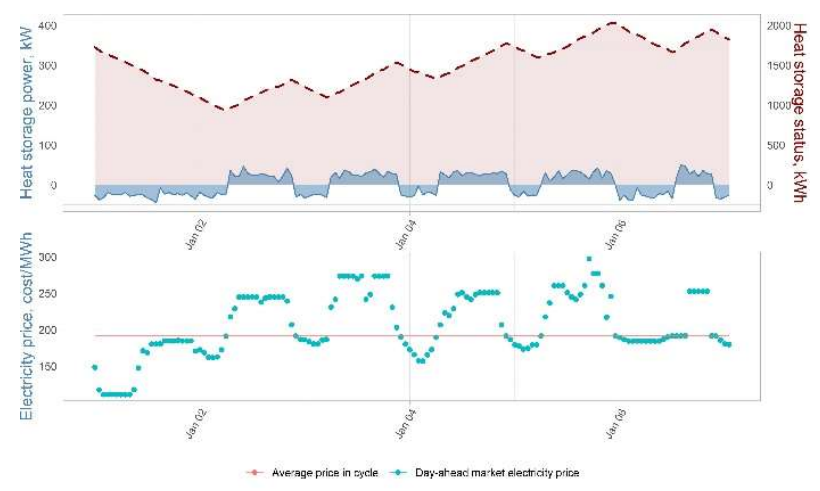

Fig. 4 Underlying concept of heat storage optimization for an example cycle

This configuration of work can be beneficial when utilizing a CHP plant that could participate in a dayahead electricity market trading. Moreover, appropriate thermal inertia shifts would have to be taken into 
account to employ the model in realistic large scale conditions. Table 1 presents the assumed genetic algorithm parameters to perform calculations as well as heat storage boundary conditions. Note that, the algorithm finds optimal arguments for each cycle, then loops over defined number of cycles searching for the optimal load distribution in each cycle.

Table 1. Assumed generic algorighm parameters and heat storage boundary conditions

\begin{tabular}{|l|c|}
\hline \multicolumn{2}{|c|}{ Genetic algorithm settings } \\
\hline Type & real-valued \\
\hline Population size & 50 \\
\hline Number of generations & 250 \\
\hline Elitism & 2 \\
\hline Crossover probability & 0.8 \\
\hline Mutation probability & 0.1 \\
\hline Heat storage capacity & $3500 \mathrm{kWh}$ \\
\hline Max heat storage power & $52 \mathrm{~kW}$ \\
\hline Starting capacity & $1750 \mathrm{kWh}$ \\
\hline
\end{tabular}

\subsection{DH substation operating with air-source heat pump}

The model simulating the operation of district heating substation with an air-source heat pump is shown on Figure 5. The basic automation of the substation is preserved. The only difference is the addition of a heat pump cycle. Heat pump intakes part of the return water stream from the consumers and heats the stream to $55^{\circ} \mathrm{C}$. Then the heat pump output water stream is mixed with remaining stream in the substation circuit and enters the main heat exchanger, where water is heated to required temperature.

Table 2 Essential heat pump parameters - design decisions

\begin{tabular}{|l|c|}
\hline \multicolumn{2}{|c|}{ Heat pump parameters } \\
\hline Condensing temperature & $57^{\circ} \mathrm{C}$ \\
\hline Evaporation temperature & $-20^{\circ} \mathrm{C}$ \\
\hline Refrigerant & Ammonia \\
\hline Heat source & Ambient air \\
\hline
\end{tabular}

To develop the most optimal and realistic model several different refrigerants were tested in conditions and parameters given in Table 2. The tested refrigerants were $\mathrm{r} 134 \mathrm{a}, \mathrm{r} 410 \mathrm{a}$ and ammonia with resulted in COP values of $2.34,2.45$ and 2.54 respectively. Thus, ammonia have been picked as a refrigerant in the cycle.

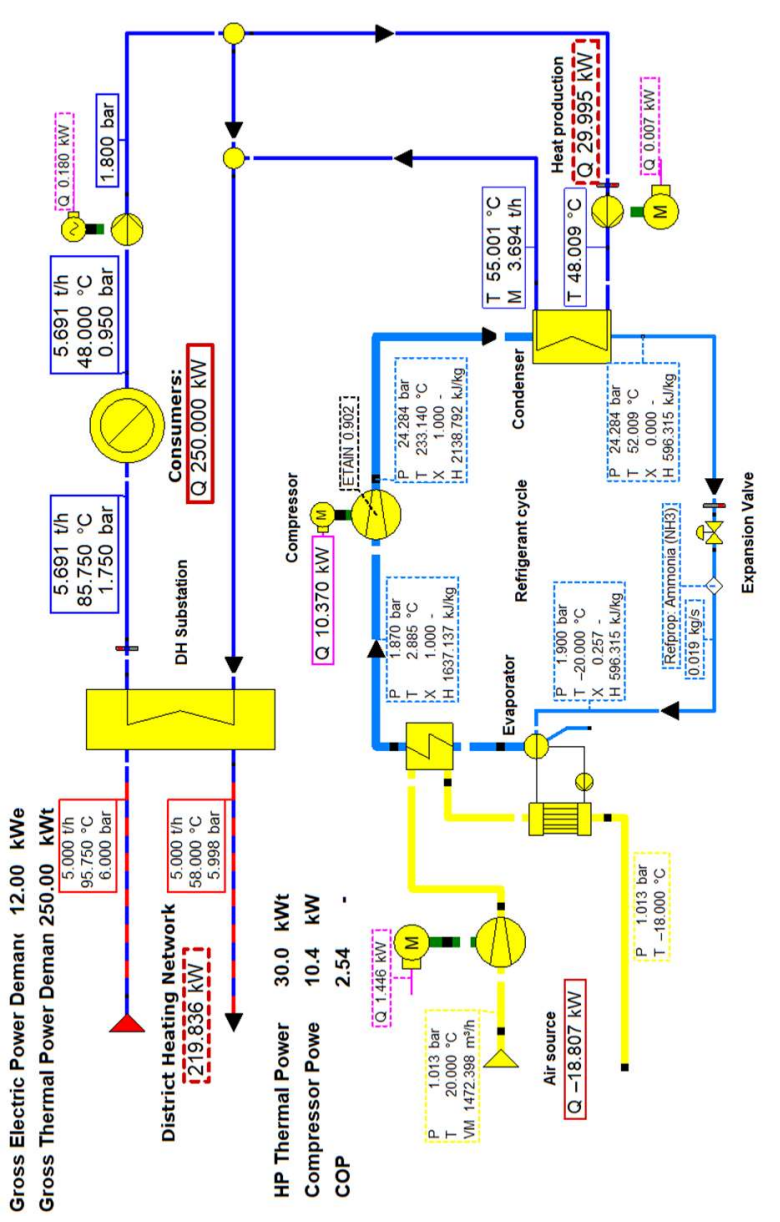

Fig. 5 DH substation operating with air-source heat pump

Based on the substation characteristics (figure 1), constant water output temperature from the heat pump have been assumed as $55^{\circ} \mathrm{C}$. Assuming lower temperatures in further considerations can be analysed to increase overall COP. However, it could limit available operating hours of the substation as too low temperature difference would lead to too high water flow rate through the condenser or would limit the power output of the heat pump. In some cases with lower demand (below $70 \mathrm{~kW}$ ), the substation cycle flow was lower than the required for the condenser. Thus, it is necessary to decrease the supply temperature accordingly (currently it was assumed equal to a measured value) or increase water output temperature of heat pump (would result in lower COP).

\subsection{DH substation operating with air-source heat pump and PV panels}

Another analysed substation scenario was identical to the one on figure 4 with difference being application of PV panels. In researched substation location there is enough space to install $6 \mathrm{PV}$ monocrystalline panels (total area of $9.84 \mathrm{~m}^{2}$ ). Meteorological data was gathered, including solar irradiance, wind speed and direction as well as ambient temperature. Based on geological coordinates, the algorithm for sun angles according to DIN 5034 was applied to calculate yearly production. Azimuth angle of collector (direction of the 
positive collector axis) was assumed as 30 degrees. Yearly electric power production from PV panels was $2542 \mathrm{kWh}$. This amount of energy surpasses electrical auxiliary power demand in existing substation, but allows only to decrease power consumption of heat pump compressor by around $1 \%$ assuming the $30 \mathrm{~kW}$ heat pump would work for a quarter of a year with average COP close to 2.5 .

\section{Conclusions}

The simplified mathematical model of heat storage tank have been prepared using $\mathrm{R}$ programming. The model can be used in conjunction with genetic algorithm to find optimal working conditions for heat storage in district heating substations.

Several different scenarios of district heating substation have been modelled. The models include renewable energy sources such as PV panels and air-source heat pump. Based on assumed data the PV panels could reduce the electric power demand of heat pump compressor by $1 \%$ in current configuration. The main limiting factor of upscaling the PV panels is available space next to the substation. Air-source heat pump with ammonia as an refrigerant can achieve COP equal to 2.54 in design conditions.

\section{References}

1. Directive 2018/2001 of the European Parliament and of the Council of 11 December 2018 on the promotion of the use of energy from renewable sources, Official Journal of the European Union, L 328/82 (2018)

2. Act of 7 July 1994 on construction law, Official Journal of Poland, Dz. U. 12, 317, 352 (2018)

3. Directive 2010/31/EU of the European Parliament and of the Council of 19 May 2010 on the energy performance of buildings, Official Journal of the European Union, L 153/13 (2010)

4. K. Ebrahimi, G.F. Jones, A.S. Fleischer, A review of data center cooling technology, operating conditions and the corresponding low-grade waste heat recovery opportunities, Renew Sustain Energy Rev, 31 (2014), p. 622-638

5. M. Rämä, M. Wahlroos, Introduction of new decentralised renewable heat supply in an existing district heating system, Energy, 154, (2018), p. 6879

6. K. Kurtz-Orecka, K. Koczergo, W. Tuchowski, The method of increasing the energy efficiency of a heat pump and the system of heat and cold supply, (Polish Patent Application WIPO ST 10/C PL425267, 2018)

7. Combined Heat and Power - Technologies, A detailed guide for CHP developers, Department for Business, Energy and Industrial Strategy (2021)

8. T. Pauschinger, Solar thermal energy for district heating, In Woodhead Publishing Series in Energy,
Advanced District Heating and Cooling (DHC) Systems (2016), p. 99-120.

9. Z. Tian, S. Zhang, J. Deng, J. Fan, J. Huang, W. Kong, B. Perers, S. Furbo, Large-scale solar district heating plants in Danish smart thermal grid: Developments and recent trends, Energy Conversion and Management, 189 (2019)

10. STEAG Energy Services, EBSILON Professional for the design of power plants

11. L. Scrucca, GA: A Package for Genetic Algorithms in R, Journal of Statistical Software, 53, (2013)

12. L. Scrucca, On some extensions to GA package: hybrid optimisation, parallelisation and islands evolution. The R Journal, 9/1, 187-206. (2017)

13. R Core Team, R: A language and environment for statistical computing. R Foundation for Statistical Computing, Vienna, Austria, (2021)

14. RStudio Team, RStudio: Integrated Development for R. RStudio, PBC (2020)

15. H. Wickham, R, François, L. Henry, K. Müller. dplyr: A Grammar of Data Manipulation. R package version 1.0.7. (2021)

16. A. Kassambara, ggpubr: 'ggplot2' Based Publication Ready Plots. R package version 0.4.0 (2020)

17. Microsoft Corporation, S. Weston, doParallel: Foreach Parallel Adaptor for the 'parallel' Package. R package version 1.0.16. (2020)

18. H. Wickham. ggplot2: Elegant Graphics for Data Analysis. Springer-Verlag (2016)

19. G. Grolemund, H. Wickham, Dates and Times Made Easy with lubridate. Journal of Statistical Software, 40(3), 1-25. (2011)

20. maldistribution of the flow of media in tube-andfin cross-flow heat exchangers, Heat Transfer Engineering, vol. 39, No. 13-14, pp. 1179-1191, 2018.

21. Hanuszkiewicz-Drapała M., Bury T., Widziewicz K.: Numerical model of a cross-flow heat exchanger with non-uniform flow of media. Journal of Power Technologies, 93 (5) (2013), pp. 295-302.

22. K.Widziewicz, Analiza termodynamiczna krzyżowoprądowego wymiennika ciepła z uwzględnieniem nierównomierności dopływu czynników i promieniowania cieplnego [Thermodynamic analysis of a cross-flow heat exchanger including a non-uniform inflow of mediums and the radiative heat transfer], $\mathrm{PhD}$ dissertation, Institute of Thermal Technology, Silesian University of Technology, Poland, 2014.

23. T.Bury, J.Składzień, Evaluation of selected methods of mitigation of media flow maldistribution impact in finned cross-flow heat exchangers. 3rd International Conference on Contemporary Problems of Thermal Engineering, 18-20 September 2012, Gliwice. 